\title{
Managing organisational knowledge through recruitment: Searching and selecting embodied competencies
}

Accepted for publication in Journal of Knowledge Management (2017)

\section{Ingvild Jøranli}

Department of Sociology and Human Geography, University of Oslo

E-mail: ingvild.joranli@sosgeo.uio.no

Phone number: +4795796290

Address: P.O. Box 1096 Blindern

N-0317 Oslo, Norway 


\section{Purpose}

The creation of customized, technology-based services is highly dependent on experiencebased knowledge embodied in individual expert employees. Therefore, knowledge upgrading through recruitment is fundamental to advanced services firms. Paying particular attention to the role of pre-existing knowledge bases and organisational contexts, this paper investigates how software services firms search and select new employees. By doing so, it addresses an underdeveloped part of the human resource management (HRM) literature that concerns the relationship between recruitment and organisational learning.

\section{Design/methodology/approach}

The analysis uses qualitative data gathered through semi-structured interviews with HR managers and executives in 12 software firms located in the Norwegian capital, and supplementary information from technologists' CVs. The firms are strategically chosen to support conceptual development and to allow theoretical generalizations that have relevance for practitioners, and for future research.

\section{Findings}

The findings point to a challenging tension associated with the need to create stable individual knowledge linkages internally in consultancy-based business environments where technologists tend to develop their careers through external labour market mobility.

\section{Practical implications}

Mangers should reflect upon the balance between external and internal competence investments. The creation of an organisational labour market (ILM) represents one way of coinvesting in integrative capabilities and thus of avoiding over-dependency on external sources of knowledge.

\section{Originality/value}

The study provides a conceptual model linking recruitment to organisational learning, and emphasises the importance of knowledge management functions at the intersection between external labour markets and the internal organisation.

\section{Keywords}

recruitment, embodied knowledge, collective capabilities, software services firms, OLM, ILM

Word count: 9700 


\section{Introduction}

A number of studies have found labour mobility to be a crucial channel for transferring knowledge across organisational boundaries (Power and Lundmark, 2004; Boschma et al., 2009; Argote and Miron-Spektor, 2011; Herstad et al., 2015). Compared to explicit and generic elements of knowledge (know-why), tacit and specific elements (know-how) are distinctively personal (Becker, 1964; Lam, 2002; Polanyi, 1958; Gertler, 2003), and therefore difficult to transfer in a disembodied manner, without losing value (Gold et al., 2001; Asheim, 2007; Jensen et al., 2007). The creation of customized, technology-based services is closely tied to the tacit and non-standardised intellectual capital of individuals (Nowak and Grantham, 2000; Lam, 2002). Such capital is reflected in the technical skills and previous projectexperiences that individuals have obtained through their career paths. Because the exploitation of embodied experiences are fundamental to the value creation of high-end services firms (Dougherty, 2004; Lusch and Vargo, 2014), recruitment is a critical mechanism for accessing cutting-edge knowledge existing external to the firm.

In her groundwork on the resource-based view of the firm, Penrose (1959) argues that the capacity to create new economic value is not only a question of a firm's resource endowments, but depends on the firm's capacity to manage its resources efficiently. The primary role of managers is therefore to maximize value through optimal deployment of resources and capabilities, and develop the firm's resource base for the future (Grant, 1996). Reflecting the endogenous perspective of resource-based theories (Kor and Mahoney, 2004), research on strategic management (SM) have tended to investigate human resource management (HRM) decisions influencing knowledge-exchange at the intra-organisational level, rather than decisions shaping inter-firm knowledge exchange (Martin-Rios, 2014). Studies investigating recruitment as an expression of inter-firm knowledge transfer are also scarce and address a crucial gap in the HRM literature (Janssen, 2014).

In response, the following study explore recruitment practices of 12 software services firms located in the Norwegian capital. The study discusses two research questions: i) Search: How do software services firms manage their external competence searches? ii) Selection: How are knowledge needs and organisational learning dynamics reflected in the selection processes? By discussing these questions, the study sheds light on recruitment as a process of connecting to external sources of knowledge (Ardito and Messeni Petruzzelli, 2017), and speaks to the question of how search channels and selection criteria mirror intrinsic organisational characteristics. Furthermore, the paper reflects on the career advancement of technologists as 
driven by inter-firm mobility versus advancements occurring within the firm (Eyraud et al., 1990; Lam, 2002), and the extent to which these trends may have implications for the collective learning capabilities of firms that operate in dynamic and open organisational environments (Teece et al., 1997; Lazonick, 2012).

The analysis uses qualitative data gathered through semi-structured interviews with HR managers and firm executives, and supplementary information from $\mathrm{CV}$ s of their newly recruited technologists. The firms are strategically chosen to support conceptual development and allow theoretical generalizations that have relevance for practitioners, and for future research. The empirical investigation provides a 'thick description' (Geertz, 1973), and by following an interpretive research strategy (Holloway, 1997), the study discusses the extent to which organisational and societal context ('culture') of the firms influence their search strategies and selection behaviour. Furthermore, the paper address conceptually whether organizational structures are shaping the creation of internal knowledge dynamics.

The second part of the paper builds on this conceptual framework when addressing, first, how recruitment as a channel to external knowledge and a crucial determinant of skillcompositions within the work force. Second, it discusses the relationship between individually embodied knowledge and collective learning dynamics (Kusunoki et al., 1998). The third part presents the industry context, research design and sample, while the fourth part presents and discusses the empirical findings. Then, the final part presents the contribution and implications of the study, and introduces a conceptual model showing the relationship between recruitment and the preliminary stages of organisational learning.

\section{Recruitment: competence search and selection}

Recruitment expresses the firm-specific capabilities to identify and access individual expert competencies developed in external firms and institutions, and the processes of selecting and integrating these into the cognitive domains of the firm (Cohen and Levinthal, 1990; Herstad et al., 2015). Phillips and Gully (2015) argue that recruitment is a key managerial function enabling the creation, development and maintenance of a firm's competitive advantage, and must therefore be aligned to other HRM functions of the firm. The manager's role in recruitment processes is evident through its primary function of enforcing the operational routine of the firm, by solving task-specific competence demands. Additionally, the manager's role is crucial in creating a meta-routine of which the operational routine of the firm is continuously being revised (Knott, 2001). According to the latter, recruitment relates 
to a broader understanding of how a firm manages its dynamic capabilities (Teece et al., 1997), that is, for example of how the skill-composition of the work force influences a firm's sustainable competitive advantage (Barney, 1991). The following framework conceptualise how recruitment relates to organisational learning and renewal (Inkpen, 1998; Segelod and Jordan, 2004; Singh and Agrawal, 2011).

A number of studies have investigated the influence of work force diversity to firm performance. In their meta-analysis, Bell et al. (2010) distinguishes between primary and secondary diversity. While primary diversity relates to given individual characteristics such as age, gender and ethnicity, secondary diversity relates to more task-related characteristics such as education, experience, thus drawing attention to the career paths of individuals (Bell et al., 2010). Østergaard et al. (2011) found employee diversity in gender, age, and education to have a positive effect on a firm's likelihood to innovate. Breschi et al.'s (2003) study shows that mobility of individuals between technologically related industries is beneficial to diversification of the firms' innovation activities. Boschma et al. (2009) found that labour mobility per se did not have an effect on firm performance, but depended on the type of skills flowing into the firm, arguing that a portfolio of related skills among employees have positive effect on productivity growth. Working communities consisting of individuals holding different experiences and backgrounds have also been considered as advantageous to the provision of knowledge-intensive services. Gianecchini and Gubitta (2012) argue that previous work experiences may influence which problems employees identify as important, how these are formulated and the type of service solution generated. Despite their differences, these studies direct along the same lines pointing to the collective learning opportunities that arises from the interaction between individuals holding educational backgrounds and worklife experiences that are diverse, but complementary.

Notwithstanding the empirical studies finding support for a positive relationship between competence diversity to firm performance, the literature is somehow ambiguous. Nooteboom et al. (2007) argue that there is a trade-off between knowledge diversity and knowledge sharing. Too much diversity translates into cognitive distances that may be harmful to teamwork, as members communicate past each other and tensions may arise from diversity of perspectives. Contrary, too similar skills may be harmful for learning dynamics, because most of the team members know more or less the same. In this perspective, the preconditions for learning and decision-making are most efficient in teams where diversity conducive to learning balances similarity conducive to communication, that is, where an 'optimal level of 
cognitive distance' is reached (Nooteboom et al., 2007). Accordingly, the extent to which a newly recruited individual hold competencies beneficial to the firm depends on how their skills and behavioural attributes matches the firm's pre-existing knowledge base and organisational routines (Cohen and Levinthal, 1990; Herstad et al., 2015).

The capacity of individuals to interact and share their knowledge and experiences is crucial in translating individual learning into organisational capabilities (Nonaka et al., 2000; Lam and Lambermont-Ford, 2010; Argote and Miron-Spektor, 2011). In order to understand the micromechanisms of knowledge sharing and recombination among individuals, Kusunoki et al. (1998) conceptualize organisational knowledge as multilayered. In this view, knowledge is stratified into three layers, where the interaction between the layers expresses the knowledge dynamics that foster learning. The first layer represents the knowledge base of the firm, concerning distinctive individual competencies. The second layer represents the knowledge frames, and concerns the internal organisational structure that determines and shapes the knowledge linkages between individuals. The third layer, called 'knowledge dynamics', emerges from the interaction between individuals, and expresses the process capabilities and learning opportunities of the firm.

This multilayered view corresponds to Kogut and Zander (1992: 384) who argue that the collective capabilities of a firm add up to more than the sum of its individual competences, claiming that firms provide 'a social community of voluntaristic action structured by organizing principles that are not reduceable to individuals'. Based on this, learning opportunities arise from the linkages and interactions between individuals talking part of the working community, and these interactions reinforce how individual competencies are being combined and recombined (Koch and Strotmann, 2008). This line of reasoning points to fundamental challenges for consultancy-based services firms. In these organisational environments, employees contribute individually in market-led projects (Lam and Lambermont-Ford, 2010), implying that they tend to interact and co-create knowledge more intensively with their clients and partners (den Hertog, 2000; Isaksen, 2004; Skjølsvik et al., 2007) than among colleagues. Consequently, compared to the model proposed by Kusunoki, et al. (1998), these working environments are characterised by relatively loosely coupled and temporary knowledge linkages, that often transcends organisational boundaries. These characteristics provoke attention towards the role of organisational contexts in the creation of individual knowledge linkages within firms. 


\section{Collective organisational framework and industry characteristics}

Lam and Lambermont-Ford (2010) characterize software firms and management consultancy firms as typical examples of 'operating adhocracies', that is, project-based organisation where capabilities derive from the diverse know-how and practical problem-solving skills of individuals. Often, these organisations are providers of non-standard, creative and problemsolving services to their clients, which implies lower degrees of formalization of work practices (Lam, 2000). This view echoes that of Maister (1982) who argues that professional services firms operate in two markets simultaneously, the market for attracting and keeping expertise (input) and the market for services (output). These two markets are intimately related because the loss of either one affects the quality of the other.

High degrees of employee autonomy is a well-documented characteristic of knowledgeintensive firms (Starbuck, 1992; Sveiby, 2001). In operating adhocracies, knowledge sharing is linked to the normative motivation among individuals to share their experiences among colleagues and other partners (Lam and Lambermont-Ford, 2010). Lam (2000) emphasise that operating adhocracies are highly innovative, yet less stable organisational form that depend strongly on support from the external labour market. Hence, the dependency on embodied experiences, autonomy and motivation for knowledge sharing raises fundamental questions concerning how firms attract individuals that, besides formal education and experience-based skills, have a work behaviour that corresponds to this distinct framework for knowledge sharing and learning (Nonaka et al., 2000; Janssen, 2014).

Building on Eyraud et al. (1990), Lam (2002) distinguishes between labour markets that are 'occupational' (OLMs) and 'internal' (ILMs). In OLMs, individuals develop their work experiences and careers through learning opportunities that arises from their mobility between firms. By contrast, individuals who develop their careers within the same organisation base their advancements on learning within it (ILM). Accordingly, managers may have different strategies for building and developing the core competencies of their firms (Teece et al., 1997). Because high degrees of inter-firm mobility is a defining characteristic of the larger ICT and KIBS sector, the divide between OLM and ILM becomes particularly interesting in the case of software services firms. ICT firms located in the industrial cluster of Stockholm have higher rates of inter-firm labour mobility among their employees, than found in other parts of the labour market (Power and Lundmark, 2004). Similar tendencies are evident within the Oslo-based KIBS sector (Herstad and Ebersberger, 2014; Jøranli and Herstad, 2017). One 
explanation may be that experienced technologists advance their careers through an occupational labour market (OLM).

High degrees of inter-firm mobility cause firms to lose firm-specific and embodied knowledge to others (Combes and Duranton, 2006). Given Grimpe and Kaiser (2010) findings, managers should therefore be aware that excessive dependency on external sources of knowledge may become a disadvantage. To prevent over dependency on external resources and influences, such investments need to be paralleled by investments in internal resource creation and integrative capabilities. Therefore, accessing external knowledge by recruiting, do not solely relate to attracting and selecting new entrants that match certain task-specific demands. Rather, managers must consider how their search and selection processes influence the overall skill-composition of the firm, the ability for individuals to create internal knowledge-linkages, the balance between external and internal competence investments and the risk of losing firm-specific competencies to others.

\section{Recruitment processes in software services firms}

The software industry has been one of the fastest growing segments of the larger knowledgeintensive services sector (Tsang, 2005; Trippl and Tödtling, 2010), and the growth of the industry reflects the comprehensive diffusion and use of ICT globally (Antonelli, 2003). The industry is characterized by rapid changes in technology (e.g., new computer languages, the development of cloud technologies), paralleled by continuously evolving market demands (e.g., growth of mobile technology software services applications). Cohen and Fields (1999) found that high degrees of inter-firm mobility among technologists is a defining characteristic of the labour market in Silicon Valley. The authors argue that employees' loyalty is more strongly tied to the craft of innovation than to a particular company. As employees move between firms, their paths overlap and create networks of information-sharing that facilitate diffusion of technological capabilities and know-how (Cohen and Fields, 1999; Almeida and Kogut, 1999; Agrawal et al., 2006).

Another defining characteristic is the tendency for software services firms, and knowledgeintensive services providers more generally, to locate in capital cities and large urban agglomerations. In addition to diversity and density of clients and partners, access to skilled labour is a key factor that may intensify the concentration of knowledge-intensive services firms in large-city regions (Shearmur, 2010; Herstad, 2017; Jøranli and Herstad, (2017). 
Prior research has emphasised the crucial role of external knowledge-linkages to software firms, by addressing the role of market- versus research-oriented linkages at different stages of the software development process (Segelod and Jordan, 2004). Trippl et al. (2009) argue that firm linkages to clients, competitors and universities are the most important sources of external knowledge among firms forming the Vienna software cluster. Their findings also suggests that software firms create knowledge linkages at national and international levels to gain access to skills and expertise not available within the cluster. Others have emphasised the influence from external network relationships in the internationalization process of small and independent software firms (Coviello and Munro, 1997). The relevance of inter-firm networks to the exchange of knowledge to software firms, illustrates the relevance of more explicitly considering the micro-level processes involved in the search and selection of external knowledge through the mechanism of recruiting employees.

\section{Methodology and research design}

The formation of inter-firm networks is characterised by the co-existence of continuity and change (Ryan et al., 2012). Reflecting a critical realist position (Bhaskar, 1989), Ryan et al. (2012) argue that research on business relationships and networks requires ontological and methodological perspectives that can deal with this complexity. In critical realism, the social world is viewed as existing independently of our knowledge about it, but is in principle knowable through cognitive practices such as science (Benton and Craig, 2011). The social world is seen as consisting of 'reality layers' that span from 'necessity' (i.e., influences on behaviour that stem from social structures and thus are relatively stable) to 'contingency' (i.e., the different choices that actors make for reasons of their own). The same causal influences (i.e., structural 'necessity') may trigger different empirically observable responses, and research may have two objectives: The first is to gain insights into the causal powers of social structures and the mechanisms by which they are transformed into (different) empirical outcomes, and to make theoretical generalizations about these influences. The second is to explain (time- and place-specific) outcomes that cannot necessarily be generalized to other contexts (Sayer, 2000; Miller and Tsang, 2011), i.e. form the basis for empirical generalizations. The primary purpose of this study is to contribute along the first dimension.

Using a qualitative research strategy, the investigation provides a 'thick description' of the search and selection practices conducted by managers and their firms. The study investigates whether intrinsic characteristics of an organisation and contemporary labour market dynamics 
act as a context ('culture') for certain behaviours to take place (Redding, 2005). Although the notion 'thick description' is associated with ethnographic studies, this paper follows a broader understanding of the notion in which the researcher's task is to describe and interpret observed social action and behaviour within their particular context (Ponterotto, 2006) and disentangle what is context-specific from more general structural influences (Sayer, 2000). The 'voices' of the participants are presented through detailed descriptions of their statements and reflections. The analysis is based on triangulation of data across the participants taking part in the study (Denzin, 1989 in Creswell and Miller, 2000). Together with the researcher's interpretation of the informants' experiences, the study seeks to contribute to theory development of the issue in question.

\section{Method and sample}

The data consists of interviews with managers and executives, and CVs of new entrants. The data were collected through semi-structured interviews. The interview guide included 25 open questions, covering firm history, technology and services provisions, competence structure, recruitment search channels, selection steps and screening criteria. The interview guide was used to give the conversation a structure and a purpose (Brinkmann and Kvale, 2015). Each interview lasted for 45-80 minutes, and was conducted at the firm's location. In addition, anonymised CVs of entrants, recruited during 2015, were collected. The data were analysed by using two methods. First, information about the firm, such as number of recruitments, types of services, and information from $\mathrm{CVs}$ was analysed as descriptive information about the firms. Second, the stories and narratives presented by the respondents were coded thematically in NVivo, and analysed in relationship to the two research questions.

The firms are strategically chosen to support conceptual development and allow theoretical generalizations that have relevance for practitioners, and for future research (Glasser and Strauss, 1967). The sampling process was directed towards getting in contact with firm representatives that held positions and responsibilities that were of direct relevance to the recruitment function of their firm. In the initial stage of the sampling, businesses classified as providers of 'computer programming, consultancy and related activities' (SIC 62.0) in the official Norwegian business register were identified (Statistics Norway, 2007). This classification criterion was set in order to create a sample of firms belonging to the same industry group in terms of output. Then, the search was limited to firms located in the housing and labour market region (Gundersen and Juvkam, 2013; Jøranli and Herstad, 2017) of the 
Norwegian capital city, Oslo. In the next phase, besides intensive research on firms' websites, a career event for technologists, a software technology conference and a HR conference were visited. The further sampling process was based on identifying firms that could represent a certain diversity of different software services niches. In addition, firms that could represent a certain diversity in terms of size (number of employees) and age were selected.

Then, firms were contacted and invited to participate in the research project, first by e-mail and then by a phone call. To verify the interview guide, three pilot interviews were conducted in advance of the data gathering. Interviews were conducted on an ongoing basis until few new elements were added in the conversations, and thus, theoretical saturation was achieved (Strauss, 1967 in Eisenhardt and Graebner, 2007). At that point, data were gathered in twelve firms (in addition to the pilot interviews). The final sample included a web-design-services firm, a system integration services firm, an e-learning technology services firm, a searchoptimizing technology services firm, and a GIS services firm, to mention some. Whether the firms had independent HR departments depended on factors such as firm size and age, or was related to more strategic concerns. Therefore, the respondents held quite different titles and positions. The respondents included four HRM directors, a CEO and a CBDO, two COOs, and four HR managers. The study is approved by the Norwegian Centre for Research Data, and the data were collected in the period from 1 August 2015 to 30 February 2016.

\section{Empirical analysis: Search spaces and recruitment channels}

Managers connect their organisations to the external environment by activating different channels and sources. A majority of the informants described recruitment as a more or less continuously running activity. Promoting the firm as open for new employees was for some seen as a part of their employer branding activities, as being solely a matter of their employee search and selection processes. One informant, the COO of an e-learning technology firm described recruitment in the following way: 'In a firm like ours, and in particular when we are investing in new niche services, to win in the labour market is all-important to us, quite simply'. A HRM director of a software technology firm providing services to the energy sector stated that they never recruited anyone in order to 'fill an empty chair'; rather, candidates had to show capacity to be a resource capable of creating their own space in their working environment. These two statements underpin how the capabilities of firms evolve by the virtue of continuous inflow of employees, and echo the work of Maister (1982), in which high-end service firms compete in two closely inter-related markets simultaneously. 


\section{Structured decisions, serendipitous events and collective searches}

From the data, it is evident that recruitment processes are shaped by impulses originating at different levels of the firms. The first and most common impulse relates to recruitment processes that are based on structured decisions made by the top-level management of the firm. Such decisions are related to long-term developmental goals of the firms (embedded in budgeting, investments, prospective pipelines and production capabilities). Second, 'ad hoc' decisions were referred to as situations where recruitment processes were initiated from serendipitous events (Fitjar and Rodríguez-Pose, 2017), described as situations where the managers had 'bumped into' an interesting candidate and this meeting initiated the later stages of the screening and selection process. A third was described as recruitment processes initiated because of needs expressed among employees within the internal community of the firm. About this last-mentioned impulse, a COO said, 'In such situations the most important function of the manager is to understand the dynamics of our projects, and then assess the situation according to our demand for new competencies, more capacity in existing competencies, or assess if the situation calls for reorganising of our existing resources'. The statement reflects the two-level function of the manager, and in particular the manager's role in revising the operational routine of the firm, through capturing a meta perspective (Knott, 2001).

This distinction between recruitments initiated from structured decisions (top-level), serendipitous events (ad hoc manager), and employee (collective) expressions, echoes the work of Phillips and Gully (2015), in seeing recruitment as part of a multi-level organisational system where decision-making is connected across different organisational levels. Yet, the data show that recruitments initiated from structured decisions tended to be more related to the ongoing and prospective operational activities of the firms, reflecting less the organisational systems and policies stated in the work of Phillips and Gully (2015). When one of the managers was asked about her firm's recruitment strategies, she replied, 'At the end of the day, our recruitments are dependent on the assignments we get, and we plan our recruitments according to our project pipeline. If we get a new assignment with a client, we immediately start looking for candidates, but otherwise we have to wait and just keep candidates interested in our firm'. This manager worked in the web-design firm, and her statement gave voice to a certain challenge of developing long-term recruitment strategies, in a firm where competence needs are closely tied to incoming projects. This is one challenge in 
operating adhocracies, in which market-based projects and continuous re-structuring of project teams make the organisation unstable (Lam, 2000).

External competence searches are embedded in structured decisions, serendipitous events, and collective expressions, and can be categorized according to the level of expertise being searched for. Recruitment of new graduates corresponds, relatively speaking, to building organisational capabilities in a long-term perspective (because these individuals need to be trained to get firm-specific experience). Recruitment of experienced technologists relates, relatively speaking, to more immediate competence demands (e.g., ongoing projects). These two levels of expertise demand different search strategies and channels.

\section{Open and closed search channels}

Recruitment of new graduates tended to be elaborated from structured decisions. In these processes, search strategies were driven by external searches aiming to connect to a larger mass of potential candidates, from which the firm could screen and select. Search approaches included participating at career events at universities and having an open attitude towards student projects and internships. In addition, publishing vacant positions on the firm's own website, other relevant online sources, and even radio advertising were mentioned as methods used by one firm. These structured search practices can be considered as occurring through open search channels. Despite the use of open search channels, one HRM director said that the firm also contacted new graduates through the networks of their own newly graduated employees. Another HR manager stated that the university career of his firm's founder was critical in his search processes. The founder's close relationship to former university colleagues provided the manager with contact points to promising university students. Thus, structured decision-making and the use of open search channels do not rule out other mechanisms used in attracting new graduates.

Compared to the use of open channels when searching for new graduates, searching for experienced technologists tended to involve the use of more directed, or closed, channels. In these situations, processes were motivated by the need to identify individuals with highly specialised skills and career paths. The use of open search channels was considered as less appropriate because these channels generated a large number of applicants, but often few applicants were qualified according to the firm's highly task-and-technology-specific field of expertise. The directed search methods were described as demanding, regarding both finding and attracting interest from candidates, mostly because these individuals were employed by someone else and not active in the labour market. One HRM director said, 'Our major cost 
and time spent on these recruitments concerns finding these people'. Another manager expressed interest in contacting only candidates that were employed, because current employment indicated the candidates' success.

In directed recruitment processes, search channels embedded within the internal community of the firm (collective) were described as crucial, besides the use of recruitment agencies and the managers' own searches. A majority of the informants recognized personal networks as a key channel in their directed and closed search processes. One HRM director claimed that by recruiting through internal networks, they reduced the risk of selecting someone that did not fit into their organisational culture and context. He argued that their employees had a high threshold for recommending someone unless they were certain that the candidate had the skills, both technical and social, that would contribute to the firm's projects and match its work practices. He claimed that their most successful recruitments were drawn from the networks of own employees.

A HR manager of a young start-up firm, expressed that the network of their founder was essential in building the firm's competence base. In this firm, many of their current employees had worked for the entrepreneur in his former start-up, and followed him to his new start-up when the former firm was bought by Microsoft. The manager argued that the name and reputation of their entrepreneur were crucial to attract experienced technologists. A COO stated that his firm had recruited intensively through personal networks for several years, but they were currently experiencing that they had exhausted all of their internal relations, because personal relations are limited. The two statements reflect the critical value of search channels embedded in the internal community (collective) and underpin the distinct value associated with the ability to exploit interpersonal networks (Robertson et al., 2003).

External partner networks represent another directed search channel; however, such channels were viewed as more complicated to take advantage of. Firstly, some firms had strict policies concerning recruitment from existing, previous, or potential clients, as such recruitment could harm their market relations. Conversely, some had experienced that employees created close linkages with clients during a consultancy project, resulting in these employees being recruited by the clients later on. Thus, close collaboration with clients could cause competence losses, more than being a competence source to the firm. To the question of which channels the firm had used in its last two recruitment processes, the CEO of a software consultancy responded that: 
...these recruitments were based on relations. In these two cases we recruited from one of our competitors. In fact, we have been collaborating with these people for a while, and suddenly we got the feeling that our competitor slowed down their investments and activities concerning their cloud technology platform. And when you work really close to people over a certain period, we just started to sense it, and after a while our dialogue got quite clear ... and we simply said, 'We need the competence you represent. Are you interested?'

Another directed search channel concerns the use of external recruitment agencies. Some informants said that external agencies provided them with an extended network to potential candidates. One manager explained her use of recruitment agencies as resulting from the firm's fast growth and lack of an internal administrative set-up that could handle the recruitment function. However, the use of external agencies was depicted as quite doubleedged. One informant described his relationship to the external recruitment agency as a trustful relation, providing him with a list of highly qualified individuals he could contact. Yet, another manager had used external recruiters in various stages of the recruitment processes, but realised that the agency took advantage of the firm-specific insight it had gained, and used this insight to recruit the firm's employees for others. Another informant addressed the difficulties of outsourcing recruitment processes, and in particular the screening phase, because external agencies seldom had sufficient insight to weigh the organisational context when giving their recommendations. The last two views reflect a certain need to balance internal and external knowledge investments, because over-dependency on external knowledge investments may be harmful to the firm over time (Grimpe and Kaiser, 2010; Ebersberger and Herstad, 2011).

\section{Selecting embodied competencies}

Having formal and explicit technology competence is a basic criterion in order to be considered for employment in the sample firms. One informant expressed this in the following way: 'The first thing we do is to look at their CV and their technology competences, then we look at previous projects and roles in which the candidate has contributed'. After screening $73 \mathrm{CVs}$, it was found that 22 of 28 newly graduated employees had obtained an educational level equivalent to a MA degree. 24 of 45 experienced technologists held a MA degree. Five entrants held a BA degree, while 17 experienced employees held a BA degree. The profiles of the entrants confirm a strong dependency on formal education, reflecting their analytical and theoretical knowledge (Asheim, 2007). 


\section{Table 1 approximately here}

While formal education represents a basic selection criterion, previous work-life experience and roles, and personality are elements that are validated throughout further screening. Usually, the selection process included interviews and technical tests, and sometimes personality tests were used to screen a candidate's embodied competencies. One informant described that his most important screening criterion was to assess whether the candidate could function as a 'translator' of technology into business. In order to validate experiencebased skills, he invited candidates to a technical meeting with one or two of his firm's senior technologists, and this meeting was essential to the final decision-making:

We see it right away! Does the candidate want to show us something? Does the candidate respond in a way that invites a discussion concerning our technology? And we [the recruiter/CEO] follow this dialogue between our own technical experts and the candidate, and we can see whether these individuals find each other in the coding process ... so, we are looking for a creative power in this dialogue.

Another informant categorized the firm's technologists according to two different types of personalities, the innovator and the structured stayer. The innovator was described as a person who learned through trial and error, and who always wanted to explore new methods and solutions. The structured stayer was described as an individual that was more concerned about doing everything methodically 'right' during the coding process. This latter type of work behaviour described an individual that tended to relate any new task or challenge to previous work and project experiences. Based on this, he saw recruitment as a relational question, and gave his own interpretation of cognitive complementarity (Nooteboom et al., 2007) when claiming that:

The ideal is to put together project teams where both types of behaviour are represented, both the innovator and the structured stayer, and not least make sure that these two seem to be able to collaborate with each other in processes of creating an innovative, but also a secure software solution.

Concerning technical testing, a third informant said that 'in these tests, we are not validating whether the candidates do things the "right" way; rather, we are looking at whether the candidates "think" the right way. We assess whether they ask proper questions and the structure of their work ...'. Besides screening technical skills, one informant said the firm was 
looking for candidates who showed capacity to contribute to discussions and informal interaction with others, saying that 'our employees are responsible for their own projects, and often they work at the client's location during the project period. These individuals belong to a working community where everyone mostly works independently, but helps each other out when needed'. Her statement reflects individual autonomy and motivation for knowledge sharing as key characteristics among employees working in operating adhocracies (Lam, 2002; Lam and Lambermont-Ford, 2010), and knowledge-intensive firms (Starbuck, 1992; Sveiby, 2001).

The dynamic tension between employee autonomy and collective community was expressed in a manager's statement: 'We are interested in finding those individuals that dare to think independently, but simultaneously show modesty in discussions with our experts who have been working within this field for years'. Furthermore, she argued, 'In our organisation, our internal "hierarchy" does not concern who has worked here the longest, or who may have the “"highest" title; rather, it concerns whom you go to if you have questions. Therefore, you are valued only for your own contribution'.

One manager expressed that his firm previously had put too much weight on the results from the technical testing in the final decision-making, saying:

We have experienced those types of developers that just carry on, doing their tasks and who think that if something is wrong in the project specification, it is not their problem. The other type, and the one we are looking for, is the one that has a kind of intuitive understanding of when something seems to be wrong and then asks for help from colleagues. But selecting employees by using such parameters is very difficult.

The manager pointed to a challenging need to screen and select individuals based on criteria that capture 'cognitions' more broadly defined, to include ways of thinking, communicating, and collaborating. Such cognitions are critical in creating internal knowledge linkages and learning dynamics (Kusunoki et al., 1998); yet, these qualities are difficult to capture through traditional testing and screening practices.

\section{Organisational learning and occupational labour markets}

Some informants' viewpoints reflect preferences and needs for developing 'organisational' labour markets (ILM) (Eyraud et al., 1990; Lam, 2002), but are constrained in this respect by the vibrancy of external 'occupational' labour markets for software services expertise. One HRM director of a GIS technology services firm argued that 'in fact, it is not the ones that want to switch work place that we want to attract. We want to get in touch with candidates 
that have not even thought about changing work place'. The reason behind this approach was to avoid selecting individuals that were too restless in their careers, which could case competence losses when the individuals later chose to move on.

Another informant also reflected on the tendency that young employees left after a few years. He suggested that the losses were attributed to the increasing attractiveness new graduates once they had obtained some years of technical experience and become legitimate 'members' of the ICT expert occupational community. Moreover, he argued that new graduates were more career oriented and willing to gain different types of work experiences during the early years of their careers. The competence loss was critical since the firm had invested time and resources educating and training these individuals in firm-specific knowledge, without being able to benefit from the investment. A HRM director described a similar situation, saying that her firm lost about $50 \%$ of their newly graduated employees, mostly to their clients:

These candidates are so sought-after by our clients, and they are spending most of their working hours with our clients, so quite often they receive a job offer. Therefore, we need to be satisfied if we are able to keep half of our graduate recruitments, and we do need to have a clear career plan for them.

The data show a certain tendency of employee outflow to clients and others, sometimes causing the firms to lose their experienced technologists as well. Some informants expressed that their experienced employees got job offers from others on a weekly basis. One manager argued that her firm needed to create a stronger sense of organisational belonging among its employees to retain them. In addition, the extensive activities of recruitment agencies may increase the degree of inter-firm mobility of technologists. Undesirable outflow of employees can affect the internal processes of converting the competencies of individuals into stable internal knowledge linkages, that ultimately interrupt the creation of organisational knowledge dynamics (Kusunoki et al., 1998). However, another informant reflected upon the loss of employees to clients in a wholly different manner. This informant argued that if the firm's clients recruited their employees, she assumed that they would become important 'ambassadors' for her firm's technology platform and services. Therefore, she argued that employee outflow could lead to new business opportunities.

Internal recruitment processes were by some described as more demanding than recruitment from the external environment. Elaborating on this difference, one informant explained that in internal processes, the firm could not exclusively focus on finding the right candidate; but 
they also had to establish a dialogue with everyone that had shown interest in the position. The informant stated that all who had shown interest had to be taken seriously when they signalled interest in doing something else. The informant said that she often was surprised by who that expressed interest, asking: 'Are these individuals unsatisfied? What kinds of ambitions do they have?' Another informant described the lack of validated methods applicable in internal recruitment processes. He reflected upon whether internal selection processes too often were based on a 'gut feeling'. He addressed situations where technologists became team and project leaders, because of the manager's general satisfaction with their project work and performance, though he did not evaluate their qualifications in relation to the prospective new role. He argued that this tendency could cause an internal brain drain of their most competent technologists, because they were moved towards roles and tasks that were more administrative than technical.

\section{Conclusions and implications}

A firm's capacity to connect to external sources of knowledge is critical to the development of organisational capabilities (Cohen and Levinthal, 1990; Teece et al., 1997; Inkpen, 1998). Nevertheless, few studies have analysed HRM decisions affecting knowledge transfer across organisational boundaries. In response, and guided by two research questions, this paper has presented an in-depth investigation of recruitment practices in 12 Norwegian software services firms. The first research question emphasises the actions taken by firms and their managers in order to connect to and attract interest from candidates in external labour markets. The results suggests that managers and executives are taking an active role in connecting their organisations to external knowledge sources, exhibiting a high degree of awareness of how these processes influence their technological capabilities and market positions. Search is a more or less a continuously running activity, involving activities and mechanisms at different organisational levels. Recruitment processes can be initiated from structured decisions and serendipitous events, but also 'bottom up' by the community of experts that constitute the services-providing organization. External searches are managed by the use of open and closed channels. In closed searches, managers preferred recruiting through the personal networks of internal members, because this channel is associated with lower risk. The personal networks embedded in the internal community of the firm are therefore critical to prospective learning opportunities and to the dynamic capability of the firms (Teece et al., 1997; Cohen and Fields, 1999). 
The second research question addresses whether knowledge needs and organisational learning dynamics are reflected in the selection processes. The organisational and societal structures are reflected in three distinct ways. First, throughout the screening process, managers carry out extensive technical testing of the candidates in order to validate their tacitly embodied experiences. The technical testing reflects a strong organisational dependency on tacit and non-standardised knowledge, characterising operating adhocracies. Yet, strong dependency upon know-how does not omit the value of explicit theoretical and formal qualifications, but the screening process is used to validate the candidates' ability to transform theoretical and abstract knowledge into customized services. Second, a challenging tension is apparent between autonomous work behaviour and extensive contribution in market-based projects, because the combination can hamper the creation of knowledge linkages within the internal organisation. Because excessive outward linkages influence individuals' sense of organisational belonging (Lam and Lambermont-Ford, 2010), managers must reflect upon the balance between inward and outward knowledge linkages among their employees.

In extension of this, and third, the dependence of firms on external 'occupational' labour markets and the tendency for technologists to develop their careers through inter-firm mobility can prevent the creation of stable knowledge linkages in the organisational community. Therefore, there is a certain need to balance external and internal competence investments. The creation of organisational labour market (ILM) is one way to make coinvestments in internal resource creation and integrative capabilities (Grimpe and Kaiser, 2010; Kleinknecht et al., 2014). Figure 1 below conceptualizes the relationship between processes of searching, selecting, and integrating individually embodied competencies into organisational systems that are open and dynamic. The left side of the figure shows how managers connect to external knowledge sources, using open and closed search channels. The knowledge management interface reflects the critical time when the firm makes the decision of recruiting a new employee. The right side links recruitment to internal capabilities, expressed in the creation of knowledge linkages that fertilize learning and recombination of knowledge within the firm.

\section{Figure 1 approximately here}


Given the findings from this study, further HRM research should put a stronger emphasis on organisational learning as being dependent on interpersonal linkages and labour market dynamics that are ultimately triggered by the behaviour of individuals. This reflection is supported by recent research into the ongoing paradigmatic shift from the knowledge economy 1.0 to the knowledge economy 2.0 (Rutten and Boekema, 2012). While the 1.0

paradigm characterises learning as organised interactions within and between firms, the 2.0 paradigm conceptualizes individuals as the main locus of learning and inter-firm relationships. Due to an organisational and contextual dependency on non-standardized embodied knowledge, autonomous work practices and extensive market interaction, the results from this study argue in favour of developing HRM strategies that integrate recruitment into longer-term competence development goals of individuals. Consequently, recruitment should not be considered as solely a tool for solving task-specific competence demands, but needs to be related to organisational learning more generally, and more fundamentally.

\section{Limitations}

Research on labour market mobility has shown that people are more inclined to switch work place within the boundaries of a region, rather than across regions. In response to the strong concentration of the KIS sector and software services in capital cities, further studies should emphasise any potential relationship between firms' recruitment practices and competences available in the external urban and regional labour markets. 


\section{References}

Agrawal, A., Cockburn, I., and McHale, J. (2006). "Gone but not forgotten: knowledge flows, labor mobility, and enduring social relationships", Journal of Economic Geography, Vol. 6 No. 5, pp. 571591.

Almeida, P., and Kogut, B. (1999). "Localization of knowledge and the mobility of engineers in regional networks", Management Science, Vol. 45 No. 7, pp. 905-917.

Antonelli, C. (2003), "The digital divide: understanding the economics of new information and communication technology in the global economy", Information Economics and Policy, Vol. 15 No. 2, pp. 173-199.

Ardito, L. and Messeni Petruzzelli, A. (2017), "Breadth of external knowledge sourcing and product innovation: The moderating role of strategic human resource practices", European Management Journal, Vol. 35 No. 2, pp. 261-272.

Argote, L. and Miron-Spektor, E. (2011), "Organizational Learning: From Experience to Knowledge", Organization Science, Vol. 22 No. 5, pp. 1123-1137.

Asheim, B. (2007), "Differentiated knowledge bases and varieties of regional innovation systems", Innovation: The European Journal of Social Science Research, Vol. 20 No. 3, pp. 223-241.

Barney, J. (1991), "Firm Resources and Sustained Competitive Advantage", Journal of Management, Vol. 17 No. 1, pp. 99-120.

Becker, G.S. (1964), Human Capital: a Theoretical and Empirical Analysis, with Special Reference to Education, The University of Chicago Press, Chicago, IL.

Bell, S.T., Villado, A.J., Lukasik, M.A., Belau, L. and Briggs A.L. (2010), "Getting specific about demographic diversity variable and team performance relationships: A meta-analysis", Journal of management, Vol. 37 No. 3, pp. 709-743.

Benton, I. and Craib, I. (2011), Philosophy of Social Science. The Philosophical Foundations of Social Thought. Palgrave Macmillan, Hampshire, UK.

Bhaskar, R. (1989), Reclaiming Reality. A critical introduction to contemporary philosophy, Routledge, New York, NY.

Boschma, R., Eriksson, R., and Lindgren, U. (2009), "How does labour mobility affect the performance of plants. The importance of relatedness and geographical proximity", Journal of Economic Geography, Vol. 9 No 2, pp. 169-190.

Breschi, S., Lissoni, F. and Malerba, F. (2003), "Knowledge-relatedness in firm technological diversification", Research Policy, Vol. 32 No. 1, pp. 69-87.

Brinkmann, S. and Kvale, S. (2015), InterViews. Learning the Craft of Qualitative Research Interviewing, SAGE Publications, Thousand Oaks, CA.

Cohen, W.M. and Levinthal, D.A. (1990), "Absorptive Capacity: A New Perspective on Learning and Innovation", Administrative Science Quarterly, Vol. 35 No. 1, pp. 128-152.

Combes, P.P. and Duranton, G. (2006), "Labour pooling, labour poaching, and spatial clustering", Regional Science and Urban Economics, Vol. 36 No. 1, pp 1-28. 
Coviello, N. and Munro, H. (1997), "Network relationships and the internationalisation process of small software firms", International Business Review, Vol. 6 No. 4, pp. 361-386.

Creswell, J.W. and Miller, D.L. (2000), "Determining Validity in Qualitative Inquiry", Theory Into Practice, Vol. 39 No. 3, pp 124-130.

den Hertog, P. (2000), "Knowledge-intensive business services as co-producers of innovation", International Journal of Innovation Management, Vol. 4 No. 4, pp. 491-528.

Dougherty, D. (2004), "Organizing Practices in Services: Capturing Practice-Based Knowledge for Innovation", Strategic Organization, Vol 2. No. 1, pp. 35-64.

Ebersberger, B. and Herstad, S.J. (2011) "Product Innovation and the Complementarities of External Interfaces", European Management Review, Vol. 8 No. 3, pp 117-135.

Eisenhardt, K.M. and Graebner, M.E., (2007), "Theory building from cases: Opportunities and challenges," Academy of Management Journal, Vol. 50 No. 1, pp. 25-32.

Eyraud, F., Marsden, D., and Silvestre, J.-J., (1990), "Occupational and internal labour markets in Britain and France", International Labour Review, Vol. 129 No. 4, pp. 501-518.

Fitjar, R. D. and Rodríguez-Pose, A. (2017), "Nothing is in the Air", Growth and Change, Vol. 48 No. $1, \mathrm{pp} 22-39$.

Geertz, C. (1973), The interpretation of cultures. Basic books Inc., New York.

Gertler, M.S. (2003), "Tacit knowledge and the economic geography of context, or The undefinable tacitness of being (there)", Journal of Economic Geography, Vol. 3 No. 1, pp 75-99.

Gianecchini, M. and Gubitta, P. (2012), "The Role of Entrepreneurs' Human and Social Capital in Knowledge-Intensive Business Services", in Di Maria, E., Grandinetti R., and Di Bernardo, B. (Ed.), Exploring Knowledge Intensive Business Services. Knowledge Management Strategies, Palgrave Macmillan, Hampshire, UK, pp. 174-192.

Glasser, B.G. and Strauss, A.L. (1967). The Discovery of Grounded Theory: Strategies for Qualitative Research, Aldine Publishing Company, Chicago.

Gold, A.H., Malhotra A., and Segars, A.H. (2001), "Knowledge Management: An Organizational Capabilities Perspective", Journal of Management Information Systems, Vol. 18 No. 1, pp. 185-214.

Grant, R.M. (1996), "Toward a knowledge-based theory of the firm", Strategic Management Journal, Vol. 17 No. S2, pp. 109-122.

Grimpe, C. and Kaiser, U. (2010), "Balancing Internal and External Knowledge Acquisition: The Gains and Pains from R\&D Outsourcing", Journal of Management Studies, Vol. 47 No. 8, pp. 14831509.

Gundersen, F. and Juvkam, D., (2013), Inndelinger i senterstruktur, sentralitet og BA regioner, Norsk institutt for by- og regionforskning, Oslo.

Herstad, S.J. and Ebersberger, B. (2014), "Urban agglomerations, knowledge-intensive services and innovation: establishing the core connections", Entrepreneurship \& Regional Development, Vol. 26 No. 3-4, pp. 211-233. 
Herstad, S.J. and Ebersberger, B. (2015), "On the Link between Urban Location and the Involvement of Knowledge-Intensive Business Services Firms in Collaboration Networks", Regional Studies, Vol. 49 No. 7 , pp. 1160-1175.

Herstad, S.J., Sandven, T., and Ebersberger, B. (2015), "Recruitment, knowledge integration and modes of innovation", Research Policy, Vol. 44 No. 1, pp. 138-153.

Holloway, I. (1997) Basic concepts for qualitative research, Blackwell Science, London.

Inkpen, A.C. (1998), "Learning and Knowledge Acquisition through International Strategic Alliances", The Academy of Management Executive (1993-2005), Vol. 12 No. 4, pp. 69-80.

Isaksen, A. (2004), "Knowledge-based clusters and urban location: The clustering of software consultancy in Oslo", Urban Studies, Vol. 41 No. 5/6, pp. 1157-1174.

Janssen, M. (2014), The Influence of HRM pracices on Innovative Work Behaviour: Systematic Literature Review, Univerity of Twente, NL.

Jensen, M.B., Johnson B., Lorenz, E., and Lundvall B.Å. (2007), "Forms of knowledge and modes of innovation", Research Policy, Vol. 36 No. 5, pp. 680-693.

Jøranli, I. and Herstad, S.J. (2017), "Urban concentration and labour market linkages in the Norwegian ICT services sector", European Planning Studies,

Keeble, D. and Nachum L., (2002), "Why do business service firms cluster? Small consultancies, clustering and decentralization in London and southern England", Transactions of the Institute of British Geographers, Vol. 27 No. 1, pp. 67-90.

Kleinknecht, A., van Schaik, F.N. and Zhou, H. (2014). "Is flexible labour good for innovation? Evidence from firm-level data", Cambridge Journal of Economics, Vol. 38, pp. 1207-1219

Knott, A.M. (2001), "The Dynamic Value of Hierarchy", Management Science, Vol. 47 No. 3, pp. 430-448.

Koch, A. and Strotmann, H. (2008), "Absorptive Capacity and Innovation in the Knowledge Intensive Business Service Sector", Economics of Innovation and New Technology, Vol. 17 No. 6, pp. 511-531.

Kogut, B. and Zander, U. (1992), "Knowledge of the Firm, Combinative Capabilities, and the Replication of Technology", Organization Science, Vol. 3 No. 3, pp. 383-397.

Kor, Y.Y. and Mahoney, J.T. (2004), "Edith Penrose's (1959) Contributions to the Resource-based View of Strategic Management", Journal of Management Studies, Vol 41 No. 1, pp. 183-191.

Kusunoki, K., Nonaka, I. and Nagata A., (1998), "Organizational Capabilities in Product Development of Japanese Firms: A Conceptual Framework and Empirical Findings", Organization Science, Vol. 9 No. 6, pp. 699-718.

Lam, A. (2000), "Tacit Knowledge, Organizational Learning and Societal Institutions: An Integrated Framework", Organization Studies, Vol. 21 No. 3, pp. 487-513.

Lam, A. (2002), "Alternative societal models of learning and innovation in the knowledge economy", International Social Science Journal, Vol. 54 No. 171, pp. 67-82.

Lam, A. and Lambermont-Ford, J.P. (2010), "Knowledge sharing in organisational contexts: a motivation-based perspective", Journal of Knowledge Management, Vol. 14 No. 1, pp. 51-66. 
Lazonick, W. (2012), "Who Needs A Theory Of Innovative Enteprise?", paper presented at the Annual Conference of the International Schumpeter Society, July 2-5, 2012, Brisbane, AU, avaiable at: http://www.theairnet.org/files/research/lazonick/Lazonick\%20Who\%20Needs\%20a\%20Theory\%20of \%20Innovative\%20Enterprise\%2020120803.pdf (accessed 12 December 2016).

Lusch, R.F. and Vargo, S.L. (2014), Service-Dominant Logic: Premises, Perspectives, Possibilities, University Printing House, Cambridge, UK.

Maister, D. (1982), Balancing the professional service firm, Division of Research, Graduate School of Business Administration, Harvard University, Cambridge, MA.

Martin-Rios, C. (2014), "Why do firms seek to share human resource management knowledge? The importance of inter-firm networks", Journal of Business Research, Vol. 67 No. 2, pp. 190-199.

Miller, K.D. and Tsang, E.W.K., (2011), "Testing management theories: critical realist philosophy and research methods", Strategic Management Journal, Vol. 32 No. 2, pp. 139-158.

Nonaka, I., Toyama, R., and Nagata, A., (2000), "A firm as a knowledge-creating entity: a new perspective on the theory of the firm", Industrial and Corporate Change, Vol. 9 No. 1, pp. 1-20.

Nooteboom, B., Vanhaverbeke, W., Duysters, G., Gilsing, V. and van den Oord, A. (2007), "Optimal cognitive distance and absorptive capacity", Research Policy, Vol. 36 No. 7, pp. 1016-1034.

Nowak, M.J. and Grantham, C.E., (2000), "The virtual incubator: managing human capital in the software industry", Research Policy, Vol. 29 No. 2, pp. 125-134.

Penrose, E. (1959), The Theory of The Growth of The Firm. Oxford University Press, Oxford.

Phillips, J.M. and Gully, S.M., (2015), "Multilevel and Strategic Recruiting: Where Have We Been, Where Can We Go From Here?", Journal of Management, Vol. 41 No. 5, pp. 1416-1445.

Polanyi, M. (1958). Personal knowledge: Towards a Post-Critical Philosophy. University of Chicago Press, Chicago.

Ponterotto, J.G. (2006), "Brief Note on the Origins, Evolution, and Meaning of the Qualitative Research Concept Thick Description", The Qualitative Report, Vol. 11 No. 3, pp. 538-549.

Power, D. and Lundmark, M. (2004), "Working through Knowledge Pools: Labour Market Dynamics, the Transference of Knowledge and Ideas, and Industrial Clusters", Urban Studies, Vol. 41 No. 5/6, pp. 1025-1044.

Redding, G. (2005), "The thick description and comparison of societal systems of capitalism", Journal of International Business Studies, Vol. 36 No. 2, pp. 123-155.

Robertson, M., Scarbrough, H., and Swan, J. (2003), "Knowledge Creation in Professional Service Firms: Institutional Effects", Organization Studies, Vol. 24 No. 6, pp. 831-857.

Rutten, R. and Boekema, F. (2012), "From Learning Region to Learning in a Socio-spatial Context", Regional Studies, Vol. 46 No. 8, pp. 981-992.

Ryan, A., Tahtinen, J., Vanharanta, M. and Mainela, T. (2012), "Putting critical realism to work in the study of business relationship processes", Industrial Marketing Management, Vol 41 No. 2, pp. 300311. 
Sayer, A. (2000), Realism and Social Science, SAGE Publications Ltd, London.

Segelod, E. and Jordan, G. (2004), "The use and importance of external sources of knowledge in the software development process", R\&D Management, Vol. 34 No. 3, pp. 239-252.

Shearmur, R. (2010), "Scale, Diatance and Embeddedness: Knowledge-Intensive Business Services Location and Growth in Canada", in Doloreux, D., Freel, M., and Shearmur, R. (Ed.), KnowledgeIntensive Business Services. Geography and Innovation, Ashgate Publishing Limited, Surrey, UK, pp. 43-73.

Singh, J. and Agrawal, A., (2011), "Recruiting for Ideas: How Firms Exploit the Prior Inventions of New Hires", Management Science, Vol. 57 No. 1, pp. 129-150.

Skjølsvik, T., Løwendahl, B., Kvålshaugen, R. and Fosstenløkken, S.M. (2007), "Choosing to Learn and Learning to Choose: Strategies for client co-production and knowledge development", California Management Review, Vol. 49. No. 3, pp. 110-128.

Starbuck, W. H. (1992), "Learning by Knowledge-intensive firms", Journal of Management Studies, Vol. 29 No. 6, pp. 713-740.

Statistics Norway, (2007), Standard Industrial Classification, Statistics Norway, Oslo, pp. 1-343.

Sveiby, K.-E. (2001), "A knowledge-based theory of the firm to guide in strategy formulation", Journal of Intellectual Capital, Vol. 2 No. 4, pp. 344-358.

Teece, D., Pisano, G. and Shuen, A. (1997), "Dynamic capabilities and strategic management", Strategic Management Journal, Vol. 18 No. 7, pp. 509-533.

Trippl, M., Tödtling, F., and Lengauer, L. (2009), "Knowledge Sourcing Beyond Buzz and Pipelines: Evidence from the Vienna Software Sector", Economic Geography, Vol. 85 No. 4, pp. 443-462.

Trippl, M. and Tödtling, F. (2010), "Innovation and the Pattern of Knowledge Sourcing in the Vienna Software Cluster", in Doloreux, D., Freel, M., and Shearmur, R. (Ed.), Knowledge-Intensive Business Services. Geography and Innovation, Ashgate Publishing Limited, Surrey, UK, pp. 167-185.

Tsang, D. (2005). "Growth of indigenous entrepreneurial software firms in cities", Technovation, Vol. 25 No. 11, pp. 1331-1336.

Østergaard, C. R., Timmermans, B. and Kristinsson, K. (2011), "Does a different view create something new? The effect of employee diversity on innovation", Research Policy, Vol. 40 No. 3, pp. 500-509. 


\section{Figure}

Figure 1: Conceptual relationship between recruitment and organisational learning Knowledge management interface

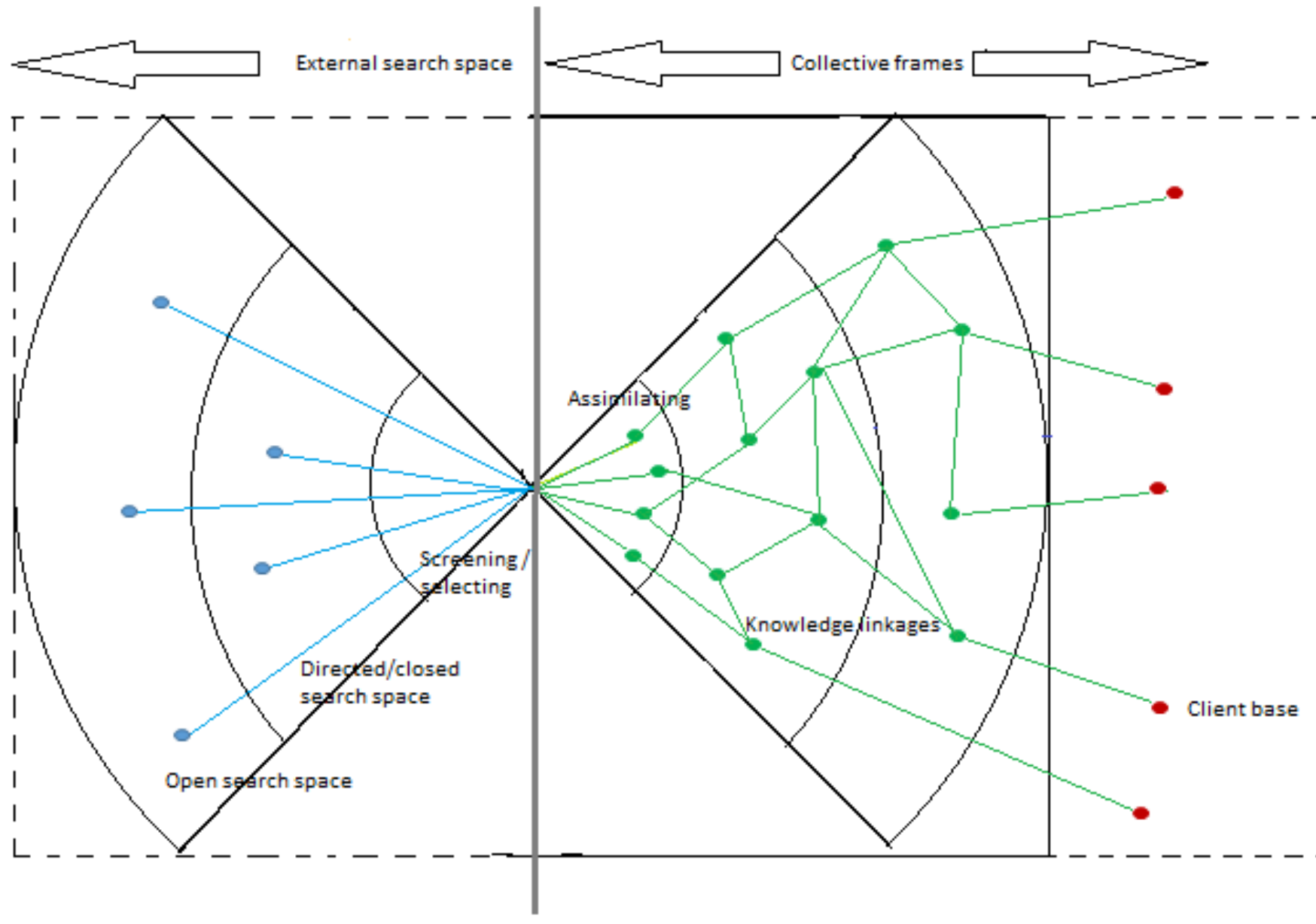

